удК 616.61-008+616.9:578.834.1]-039.74

Кузнецова И.В., Шраменко Е.К., Толстова Н.В.

ГОО ВПО «Донецкий национальный медицинский университет им. М.Горького», Донецкое клиническое территориальное медицинское объединение (ДОКТМО) ДНР, г.Донецк

\title{
ПОЧЕЧНАЯ ДИСФУНКЦИЯ У ПАЦИЕНТОВ С COVID-19 В ОТДЕЛЕНИИ ИНТЕНСИВНОЙ ТЕРАПИИ
}

\section{РЕФЕРАТ}

У пациентов отделений интенсивной терапии (ОИT) с COVID-19 частота развития острого почечного повреждения (ОПП) достигает 25\% и является независимым предиктором летального исхода. Многофакторный характер поражения почек при COVID-19 предполагает дифференцированный подход к профилактике и терапии почечной дисфункции.

Цель работы -изучение частоты встречаемости и характера ОПП у пациентов ОИТ с тяжелой формой течения коронавирусной инфекции и оценка эффективности проводимой нефропротективной терапии.

Проведен ретроспективный анализ 157 историй болезни пациентов с COVID-19, находившихся на лечении в ОИТ. Показанием для перевода в ОИТ у всех пациентов была прогрессирующая острая дыхательная недостаточность: при поступлении показатель $\mathrm{SpO} 2$ не превышал 67,8 \pm 8,5 \% при FiO2=0,21. Респираторная поддержка в виде неинвазивной вентиляции легких (НИВЛ) проводилась у 138 больных. У всех пациентов были выражены признаки системной воспалительной реакции в виде умеренного лейкоцитоза, гиперфибриногенемии, резкого повышения уровня СРБ, ферритина, лактатдегидрогеназы (ЛДГ), ИЛ-6. Повышение уровня креатинина, соответствующее различным уровням шкалы RIFLE, было выявлено у 37 (23,5\%) пациентов, из них у 27 больных ОПП развилось на фоне сахарного диабета и гипертонической болезни. У 6 пациентов в анамнезе был инфаркт миокарда и сердечная недостаточность со сниженной систолической функцией левого желудочка. У 3-х пациентов высокий уровень креатинина (1-I, 2 - F по шкале RIFLE) был обусловлен на- личием хронического гломерулонефрита и подагры.

Причинами развития ОПП, помимо прямого вирусного повреждения, в 75\% случаев были острые циркуляторные расстройства в результате нарушения водно-электролитного баланса, сгущения крови, стойкой гипотонии еще до поступления в ОИТ. В 25\% случаев к ОПП привели токсические воздействия на фоне приема нефротоксичных препаратов на предыдущих этапах лечения (ванкомицина, гентамицина, L- лизина эсцината, фуросемида, нестероидных противовоспалительных препаратов). Консервативная нефропротекция с учетом ведущих патогенетических механизмов позволила улучшить почечную функцию у 10 выживших больных.

\section{ВВЕДЕНИЕ}

Больные с COVID-19 представляют группу особого риска для развития острого повреждения почек (ОПП), особенно при наличии таких сопутствующих заболеваний, как сахарный диабет (СД) и гипертоническая болезнь (ГБ). Развитие ОПП является одним из важных факторов риска летального исхода у этой категории пациентов [1]. Изучение точных механизмов, лежащих в основе почечной недостаточности при COVID-19 и разработка на этой основе оптимальных методов терапии ОПП позволят улучшить результаты лечения [2].

\section{ЦЕЛЬ}

Изучить частоту встречаемости и характер ОПП у пациентов в ОИТ с тяжелой формой течения COVID-19, провести анализ эффективности проводимой ренопротективной терапии.

МАТЕРИАЛ И МЕТОДЫ

В ОИТ ДОКТМО с 23.10.20г по 13.03.21г (141 день) всего пролечено 157 больных с тяжелым 
течением COVID-19, из них женщин - 89 (57\%), мужчин - 68 (43\%). Возраст пациентов: 65 лет и старше - 90 (57,4\%), 40 - 64 года - 62 (39,3\%), до 40 лет - 5 (3,3\%) человек.

В ОИТ пациенты поступали, как правило, на 8-12 день болезни с клиникой тяжелой острой дыхательной недостаточности (ОДН). В пробах крови, помимо общеклинических, биохимических и коагулологических показателей, контролировали в динамике маркеры воспалительной реакции: С-реактивный белок (СРБ), ферритин, лактатдегидрогеназу (ЛДГ), иЛ-6, д-димера, прокальцитонина.

Лечение проводилось согласно действовавшим на анализируемый период Временным Методическим Рекомендациям Российской Федерации (8, 9 и 10 версии).

Статистическую обработку полученных результатов проводили с помощью компьютерного анализа (программы Microsoft Excel, Statistica и MedStat v.4.1).

РЕЗУЛЬТАТЫ

При поступлении в ОИТ у всех пациентов была выражена ОДН: SpO2 - 67,8 \pm 8,5 \% при FiO2=0,21. Неинвазивная вентиляция легких (НИВЛ) проводилась у 138 (87,8 \%) больных длительностью от 2-х до 52 суток. Перевод на ИВЛ осуществляли при сохранении гипоксемии, признаках повышенной работы дыхания, усталости пациента, нарушении сознания, неэффективности проводимой терапии, в том числе и НИВЛ.

В анализах крови отмечали умеренно

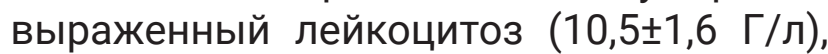

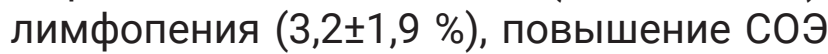

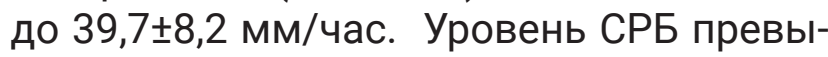
шал референсные значения в 100-700 и более раз, ферритина - в 10-12 раз, ЛДГ - в 2-3 раза, ИЛ-6 - в 4-6 раз. У всех больных отмечалась гиперфибриногенемия

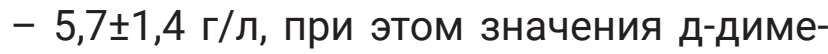
ра не всегда были критично высокими: колебания от 0,64 мкг/мл (норма <0,44 мкг/мл) до 7,2 мкг/мл. Повышение уровня креатинина, соответствующее различным уровням шкалы RIFLE, было выявлено у 37 (23,5\%) пациентов, из них у 27 больных ОПП развилось на фоне сахарного диабета и гипертонической болезни. У 6 пациентов в анамнезе был инфаркт

11 Кузнецова И.В. и соавт. миокарда и сердечная недостаточность со сниженной систолической функцией левого желудочка. У 3-х пациентов высокий уровень креатинина (1- I, 2 - F по шкале RIFLE) был обусловлен наличием хронического гломерулонефрита и подагры.

Базовая медикаментозная терапия: до $10-x$ суток от начала заболевания из этиотропных препаратов применяли фавипиравир и умифеновир. Из средств патогенетической терапии, согласно действующим протоколам лечения, использовали противовоспалительные средства (глюкокортикостероиды, ГКС), генно-инженерные биологические препараты (ГИБП) и антикоагулянты (низкомолекулярные или нефракционированные гепарины). Рекомбинантные человеческие антитела к рецепторам иЛ-6 получили 19 больных: тоцилизумаб (Актемра) - 12 и левилимаб (Илсира) - 7. Рекомбинатные человеческие антитела, нейтрализующие биологические эффекты фактора некроза опухоли-а (ФНО-а), - адалимумаб (Хумира и Далибра) были назначены 24 пациентам. Иммуноглобулин нормальный человеческий для в/в введения (Привиджен) был использован у 34 больных.

Мероприятия ренопротективной терапии: коррекция гипоксии, восстановление нормоволемии, улучшение почечного кровотока, стимуляция диуреза и коррекция дизэлектролитемии.

Анализируя механизмы развития почечной дисфункции, пришли к заключению, что при COVID-19 у пациентов развивалось ОПП преренального и ренального циркуляторно-токсического генеза. При этом большинство пациентов имели факторы риска формирования нефропатии еще до инфицирования вирусом SARS-CoV-2: возраст превышал 65 лет у 57,8 \% пациентов, имела место тяжелая сопутствующая соматическая патология (ИБС, сахарный диабет, ожирение, гипертоническая болезнь). Особенностями течения ОПП у пациентов с COVID-19 были выраженные циркуляторные нарушения, сгущение крови, дизэлектролитемия на фоне тяжелой гипоксии. Эти нарушения в большинстве случаев поддавались консервативной терапии, направленной 
на коррекцию гипоксии, восстановление нормоволемии, улучшение почечного кровотока, стимуляцию диуреза и коррекцию дизэлектролитемии. Показаний к заместительной почечной терапии у них не было. Из 37 пациентов с ОПП тяжелая форма (F по шкале RIFLE) , была только у 3. У 1 пациента по мере регресса признаков ОДН на фоне проведения нефропротекции восстановился диурез и нормализовались показатели азотистого обмена, а у 2-х больных отсутствовали условия для проведения гемодиализа (неуправляемая гипотония на фоне введения больших доз симпатомиметиков).

Из 157 больных 76 летальных исходов (46 \%)на фоне прогрессирующей ОДН. Выявлены гендерные отличия в летальности: женщины - 41,6 \% (37), мужчины - 57,4 \% (39). Летальность пациентов с ОПП - 53,4\%.

\section{ВЫВОДЫ}

1. ОПП различной степени тяжести встречается почти у $25 \%$ пациентов. В $75 \%$ случаев ОПП имеет преренальный характер, связанный с острыми циркуляторными расстройствами. У $25 \%$ больных к ОПП приводят токсические воздействия, преимущественно на фоне приема нефротоксичных лекарственных препаратов.

2. Консервативная ренопротективная терапия, направленная на обеспечение нормоволемии и улучшение почечного кровотока у больных с ОПП, эффективна в большинстве случаев. Увеличение скорости и объема диуреза приводит к восстановлению функции почек без заместительной почечной терапии.

\section{ЛИТЕРАТУРА:}

1. Шамхалова М.Ш., Мокрышева Н.Г., Шестакова M.B. COVID-19 и почки /Сахарный диабет, 2020;23(3):235-241.

2. Cheng Y., Luo R., Wang K. et al. Kidney disease is associated with in hospital death of patients with COVID-19 /Kidney Int. 2020, 97: 829-38
Сведения об авторах

Кузнецова И.В. - д.мед.наук, профессор, каф. анестезиологии, интенсивной терапии, медицины неотложных состояний ГОО ВПО «Донецкий национальный медицинский университет им.М.Горького».

Адрес: пр. Ильича, 16, г. Донецк, 83003. Email:kiv@mail.ru

Шраменко Е..К. - д.мед.наук, профессор каф. анестезиологии, интенсивной терапии, медицины неотложных состояний ГОО ВПО «Донецкий национальный медицинский университет им.М.Горького». Адрес: пр. Ильича, 16, г. Донецк, 83003. Email: k.shramenko@gmail.com

Толстова Н.В. зав.отделением реанимации Донецкого клинического территориального медицинского объединения. Адрес: пр. Ильича, 14, г. Донецк, 83003. Email: oitdoktmo@mail.ru 